\title{
Egg and Sperm Donors: Parental Identity Formation
}

\author{
Mali Mann, M.D* \\ Department of Psychiatry and Behavioral Sciences, Stanford University Medical Center, 550 Hamilton Ave, Suite 210, Palo Alto, CA, United States
}

*Corresponding author: Mali Mann M.D, Department of Psychiatry and Behavioral Sciences, Stanford University Medical Center, 550 Hamilton Ave, Suite 210, Palo Alto, CA 94301, United States; Tel: 650-325-8762; E-mail: mannm@stanford.edu

Received: February 08, 2019; Accepted: February 19, 2019; Published: February 26, 2019;

Infertility is a medical condition that affects many aspects of human life. It does affect one's relationship with self and consequently will impact one's self- Identity as a mother or father. Individuals who resort to Assisted Reproductive Technology methods will recognize the emotional impacts, physical, social and as well as economic hardship on their families.

How individual deal with these unexpected emotions, depends on one's personality style, coping mechanism and external and familial support systems.

Often facing infertility and having to deal with its traumatic impact leads to denial and projection. The traumatic loss of one's ideal self makes it a challenge for the individual who has to deal with infertility. One cannot rely upon secondary process thinking. The unconscious wishes will always be carrying reason along in the course of the decision making process and what goes into choosing egg or sperm donor.

In considering the psychological implications of ART, here we first discuss the various reproductive technologies available to couples. There are many resources that patients can access to learn about infertility, reproductive facts and Assisted Reproductive Technology. They can also access mental health professionals to help them with their unresolved emotions regarding their infertility, use of egg and sperm donor or surrogate mother.

In the United States, the American Society of Reproductive Medicine (ASRM) has been instrumental in providing specific educational resources to guide people who are facing infertility. American Fertility Association (AFA) is an organization created to educate the public about reproductive disease and support families during struggles with infertility and adoption, (http://www.theAFA.org)

In the United Kingdom since 2005, the child who is the product of egg donation can now find out non-identifying information about its donor at sixteen, and more detailed information, including name and address, when it reaches eighteen. Although the numbers of egg donors didn't collapse after this, as feared, fewer new donors registered and there has been a shortage as demand has increased - around 1,300 women every year in the UK are treated with donated eggs - with waiting lists of around a year at some clinics, which has resulted in many women and couples seeking treatment abroad. In the UK, the number of women treated using donor eggs has hovered around 1,300 every year since 2007 [1]. (The Guardian, Dec 12, 2012).
The new trend is to air for openness and transparency when individuals resort to egg donors and sperm donors, much similar to what adoption is now a days. More parents do plan to tell such children how they were conceived. There are counseling centers that help couples on how best to do it. Anonymity and secrecy is no longer in fashion. There are still some cases that do not dare to break the secrecy, since struggle with stigmatization, fear of forming weaker attachment bonding and inner conflicts.

Many gay and lesbian couples pioneered openness about using donors; many form relationship with their child's biological parent.

Today, one in every 100 babies in the U.S is created through some form of in vitro fertilization, or IVF, even many heterosexual couples like to tell their children this modern-day version of the facts of life. (npr report) http://www.npr.org/2011/09/17/140476716/a-newopenness-for-donor-kids-about-their-biology When and how to tell a child about biological genes, depend on the child's developmental and cognitive capacity to understand the meaning of the information they receive. Dishonesty affects the child's sense of trust toward their parents. It potentially creates disequilibrium in their psychic function and object relation.

\section{Egg Donors}

For woman with premature ovulation failure woman's ovaries, advanced age, lower ovarian reserve, autoimmune disease, failed IVF, or concerns about genetically transmitted disease, donor egg IVF may be considered. When in-vitro fertilization treatments are not effective, donor eggs can allow an infertile woman to carry a pregnancy to term and give birth. In men with deformed or absent sperms, the use of a technique called, ICSI (Intra Cytoplasmic Inoculation) could potentially present risks to the future child.

Although egg donation is scientifically analogous to artificial insemination with donor sperm, it raises questions concerning the medical risks and potential psychological impact on the mother, couple, and future child. The risks include expense to the woman donating the egg, the risk of carrying multiple babies to term, as well as ethical and legal issues involved in egg donation that have yet to be resolved. There are many psychological, social, and economic issues associated with the use of ART.

During the course of infertility work up, the attention is often focused on the external medical team than an individual's mind and unconscious fantasy life. The new infertility techniques help many 
infertile women to get pregnant, but the interaction between fantasy and reality stimulated by the adult wish for a baby (Pines, 1972) is complicated both before conception and during the pregnancy and the concerns transference feelings toward the donor egg or donor sperm.

After consultation with the reproductive physician, the couple can meet the egg donor though the donor egg coordinator in conjunction with the physician. Psychological issues often appear during the selection process. Some of these cases need help with the entire Egg IVF treatment, donor selection, cycle coordination, egg retrieval, and transfer of embryos.

Unlike their European colleagues, reproductive specialists in the U.S. tend to transfer multiple embryos at a time, resulting in an increased risk of multiple birth pregnancies. Although patients have opportunities to explore the concrete details of IVF available in clinician offices or on websites, they often do not explore their own internal fantasy construct. One example of denial of what reality may present is dealing with multiple babies. There is potential for both pleasure and peril in carrying multiple babies to term and parenting multiples; however pre-warning educative stance could be the most crucial task of reproductive physician and his team.

\section{Sperm Donor}

Some men must confront their own infertility issue once the actual infertility like their female counterparts.

In approximately $40 \%$ of infertile couples, the male partner is either the sole or a contributing cause of infertility. There may be abnormality related to the volume or amount, motility, and morphology of the sperm. A male fertility work up can involve genetic testing and other hormonal testing. In some cases, no obvious cause of poor sperm quality can be found.

Treatment for male factor infertility may include antibiotic therapy for infection, surgical correction of varicocele (dilated or varicose veins in the scrotum) or duct obstruction, or medications to improve sperm production. In some men, surgery to obtain sperm from the testis can be performed. In some cases, no obvious cause of poor sperm quality can be found. Intrauterine insemination (IUI) or IVF may then be recommended.

When the male infertility is the cause of the problem, individual has the option of choosing a sperm donor. Direct injection of a single sperm into an egg called ICSI, (intra-cytoplasmic sperm injection) may be recommended as a part of the IVF process. In men with deformed or absent sperms, the use of this technique could carry some risks. The physician may recommend using a sperm donor. Insemination with donor sperm may also be considered if IUI is not successful or if the couple does not choose to undergo IVF. Psychologically, men are not immune to devastating feelings of despair when you discover they are infertile.

Men might feel infertility as loss of success-that is as failure or life crisis. As one of my male patients described his feeling of failure, he felt his life came to disequilibrium. He felt a chronic sense of fear and anxiety that felt unending. The recovery from the loss may never reach to a full resolution. The mourning period can linger on for a long time and becomes an unfinished mourning in some cases. A good number of cases are unable to ask for help to process the intense feeling of disappointment to recover from the loss. The feeling of "Why me", in particular can erodes one's sense of self-confidence and self-doubt sets in.

\section{Cases}

Here we describe three cases in psychodynamic psychotherapy that illustrate the complex psychological ramifications of fertility and the impact of ART.

\section{Nelly}

Nelly is a 32-year-old married woman, who came to psychotherapy treatment for depression. She was unhappy in her life, suffered from poor self-esteem and harbored ambivalent feelings towards getting pregnant.

There was no history of childhood disturbances and she was used to being an only child. She had close healthy attachment to her mother. Her developmental milestones were reportedly normal. She had no memory of any other caregivers besides her mother.

Unconsciously she identified with her mother who denigrated her stepfather. Her mother was not a nurturing woman and was often angry with Nelly when she was a young child. In contrast her stepfather was a caring man who showed affection toward her. As a child, she was under the impression that she was conceived out of wedlock. After Nelly turned sixteen, her mother told her that she was conceived with the help of a sperm donor. Her mother refused to tell her whether she had used a sperm bank or the sperm from a friend or acquaintance. Her world suddenly became upside down--not knowing anything about her origin. Her sense of identity was shaken up. Initially shocked by this tightly kept secret. Nelly became depressed when she could not find out the identity of her biological father. She was angry with her mother who concealed the truth from her. She developed an obsession with the thought of wanting to find her biological father.

She needed to know where her chin or nose came from and also why she developed an interest in international relation and crosscultural psychology. She finally was able to find her father through Internet search after a long detective work. She wanted to solve the puzzle of "Who am I?"

Nelly hoped to forgive her mother for having her out of wedlock, and that someday her mother would tell her about the man whom she got pregnant. She started to understand her mother anxiety about her biological clock and uncertainty about her sense of femininity.

Her mother explained that she was not sure she could marry at age 34 and the clock was ticking away. She did not think she could attract a man to marry her. She decided to use anonymous sperm donor. She told her that her doctor helped her with an anonymous sperm donor. She wanted it to be something like an immaculate conception. Nelly's mother for reasons of her own did not tell her how she was conceived or where she found the sperm donor. She did not think that far ahead 
about Nelly's future inquiry into her root. All Nelly knew was that the man she called Dad was not her biological father. None of her friends knew that Nelly had stepfather.

Once Nelly became aware of the intensity of her chronic anger toward her mother, she decided to get psychotherapeutic help. She felt frozen in her life and could not move forward.

She was in tear one day and said she cannot free herself from her rage. "I don't understand why my mother did not think about what would happen to me when I had to live in her secret world of lies and deceit! Did she want empathy from me that she was not marriageable and she had to resort to lying to everyone especially to me? I am a person too".

After she discovered the biological father, she became angry with him as well. One day she related, "Now I know who was the donor I am angry with him too. It is like staying anonymous and absolved from his responsibility finished his job! I feel miserable. My mother brought me into this world just to please herself by affirming her feminine and fertile self".

In therapy, she worked on her revived deep sense of shame and narcissistic disappointment. She was ashamed of herself and her mother who lacked self-confidence. She had anxious fantasies that she was joined with her mother eternally and could not find her own autonomous self. She worried her rage would destroy her connection with her mother. Her fear of losing her god-like father of her childhood image of her stepfather mixed with a newly emerging image of this other "father", these fears turned into an anxiety about her identity diffusion. She felt regret for getting herself into "this mess" without knowing how to get out of it. She wondered about repeating what her mother had done. She fantasized about staying and childless to get revenge from her mother. She did not want to let technology decide her conception. She struggled with her husband's wish for wanting to have children.

She became aware of her ambivalent feeling about "motherhood" and was willing to work through her childhood wish to conceive and bear a child. She learned to value her academic achievement, which was so much greater than her mother's without having to feel guilty of surpassing her.

\section{Todd}

Todd and Sherry, as a couple, parent of a four-year-old son came to see me because Todd had difficulty relating to their son. He was conceived through using sperm from a sperm donor who was a friend of family and Sherry's eggs.

Sherry was 35 when after many years of trial to get pregnant; the male infertility was identified as the main factor in failing to conceive. Todd recalled the sense of failure was made infertility so difficult to deal with. It felt like a crisis for him and he went through cycles of hope, fear and despair. It felt for like an emotional roller coaster each time they started a new round of ICSI. After multiple trials, they came to accept the fact that they had to use a donor sperm. He wanted to use his close friend's sperm and his wife agreed to that. When Sherry became pregnant, they were able to go through feeling of anticipation and excitement together as a couple. The pregnancy was uneventful their healthy baby boy was born. He was a beautiful boy who did not resemble Todd.

He found himself feeling surprised having noticed some strange feeling toward his infant son and his friend with whom he had a close friendship and working relationship. In retrospect, he started to have doubting feeling about his decision using his friend's sperm rather going to a sperm bank. It felt right to ask his good friend at that time, but after Sherry gave birth to their son, he noticed he was having many doubts about his ability to be a good father. How could he have ignored his own longing for biological relationship to his child? After all many people went to "Cryobank" and arranged to get donor sperm. He felt his decision asking his friend was a reasonable one at the time. He did assume the biological root did not matter and what mattered was "the end product". He secretly blamed his wife for rushing to get pregnant. Now that their son is four years old, he looks so much like his friend Peter. He avoids getting together with Peter because he worries his son would show more affinity to Peter as well as Peter towards him.

He wondered if he could ever have the stamina keeping the secret from his son. He worried if he discloses to his son about his genetic root, he would turn away from him. Did he strip his son from the right to know who both of his parents came from? How can he and his wife explain all of these to him?

He argued with himself that his son has the right to know that Todd is not his biological father. Furthermore, he feared his friend Peter would someday reclaim his right as biological father. He kept wondering what would happen to their marriage when all three of them would attend gatherings especially when they would also take their son with them. What if Sherry developed closer connection to Peter and consequently ends their marriage.

The new dilemma he was facing caused the two of them a lot of tension. Sherry communicated to him it was his entire fault that they had to resort to his friend for help. She reminded him that she preferred an anonymous donor. They did yell at each other and it seemed like they could not agree about anything especially when it came down to decisions about the kind of day care their son was to attend or issues around discipline rules. He recalled how he felt mixed, when there was an expectation to be a hand holder when Sherry was going through pregnancy.

He did not have time to think through his decision and was expected to offer Sherry emotional support. He did not know he had come to terms with his own infertility let alone to play a new role supporting his wife. He did not know how he could offer support especially when another man's sperm was involved in this process. The sense of profound failure as a male was a prevailing feeling. He was there for her when she went through wrenching experience of the harvesting of the ova, but now he felt as if his son was a stranger. Now only in retrospect, he was able to think more deeply and wondered what effect his consenting to use donor sperm would have had on his sense of father identity and paternity right of their son?

He tormented himself with another question; his fear of seemingly weakened bond with his son. He wished he could have foreseen and prevented psychological complications of his rushed decision. 
In his therapy Todd was able to discuss all of his many fears and self-doubt as non-biological father as well as his role as husband to Sherry. He felt he had to prepare himself to be less emotionally reactive or erratic when he encountered his friend. After all, he could not be ungrateful to his friend, since he was an honorable, altruist man who helped to create their son.

He just could not believe that his feelings were going to be so out of control after the baby was born. He agreed to freeze two of Sherry's embryos for the future use. He resented the thought of having more kids, fearing having to endure the same familiar range of intense emotions. The emergence of a powerful destructive fantasy was explored during this period of his work with me. How could he deny Sherry for wanting to have more babies?

His individual therapy helped him to work through his destructive feelings, mange his intense negative affect, develop a better tolerance, and not acting out on them. After much individual work, He became interested to start couple therapy. He felt he was in a much better place since he developed a more consolidated sense of himself. He wanted to work on stability of his marital relationship.

From a post therapy contact by phone, Todd appeared that his relationship with his son improved and overall he was able to enjoy a healthy relationship with him. He learned the importance of openness and wanted to tell his son about the sperm donor when he was at a right age to comprehend it's meaning. His son temperamentally resembled him but not physically.

\section{Emily}

Emily a married professional of 45 came to therapy because of conflicts about her desire to become a mother and martial problem. She was doubtful about their capacity to become parents.

She postponed her decision to have a child for many years and suddenly realized time was running fast. Emily was the second child from a family of three children. Her sister was five years older than her and was very popular girl. She could never be like her sister and she felt her mother preferred her sister because they both were brunet and had more in common. Emily was blond and petit. The youngest was a girl who was born eight years after her birth. Emily grew up with a pervasive feeling that she was damaged, a feeling that was reinforced by her over anxious mother throughout her childhood. She was maternal to her younger sister and fiercely competitive to her older sister. Her father drank a lot and used fowl language when she was drunk. She learned to avoid him and his abusiveness.

Emily was an obedient girl who thought she was not intelligent. Her mother constantly compared her to her older sister and her father jokingly called her dumb little blond. She was filled with anxiety and self-doubt. Her family was struggling financially, and she felt inferior to her class -mates who were living in comfort.

In her early adolescence, she befriended a girl from a high socioeconomic class. She could ride in her friend's car going to school while enjoying the association to her friend's especial privilege of being driven by her chuffer. She felt envious of her friend and secretly wished she could be her. Her friend's grandfather, a financially prominent man lived with his Emily's friend's immediate family. He touched her chest several times inappropriately during her pubescent years. She recalled those early experiences exciting and at the same time was fraught with shame and guilt. Her friend's move to another school put an end to it. She liked the attention the old man was giving her by having her sit on his lap. She never told anyone about this.

Emily finished her high school years and was able to enter a prestigious collage. She met her husband in collage and after short few months, they decided to get married. The couple waited for few years before they decided to give it a try to conceive.

Their trials for conception failed for few years and finally the gynecological work up revealed multiple calcified fibromyoma in her uterus. Her mother also suffered from the same problem. However her mother had her three children before her fibromyoma became problematic. Additionally Emily's contributing psychological component complicated further to her infertility problem. Her difficulty conceiving made her feel as though she was "damaged goods". She could not become a mother unlike her mother and sister. She was bitter and could not accept that her uterine abnormality was an important reason for not conceiving. She felt it was not fair that her sister had children and she could not get pregnant. She was a "virtuous good girl" and her mother relied on her when her family needed help. She felt she was denied something very important, meaning getting pregnant like anyone else. "It was my birth right, it was not fair!", one day she uttered, and she wanted me to agree with her.

On the other hand, after she found out she could not conceive, she thought "there was a big sign on me like in Scarlet letter that I was Infertile". The fertility clinic told her she needed to talk to a psychiatrist because her infertility was "psychogenic". I was going to a full circle. I thought I was grieving. I was so disappointed each time I tried. My husband was not grieving. But, to be fair to him he actually was very supportive of me and left me free to make a decision how to go forward. He even was willing to be childless if I wanted to.

In one of her analytical hours, she said "I must have made myself infertile by being neurotic. See, I am not smart to catch on to things quickly. See, pregnancy may never happen for me. May be I wanted too much like I wanted my friend's wealth and prestige. I wanted to wear expensive clothes, drive expensive car and marry a rich man. It may want everything or wanting too much, being greedy has to do with not getting what I really want, a family is what I have always dreamt of." She had tears in her eyes. She was in despair and full of doubt. She continued, "I did not even ask why I needed to talk to a psychiatrist. I followed their advice. Looking back I could tell why I needed to see someone and now I am here to see you in order to understand my ambivalence feeling about motherhood."

She felt she needed me to help her learning to accept her fate, or maybe she would regain her stamina to pursue other options such as using egg donor or resigning to the prospect of being childless.

She had contemplated using a surrogate mother but wanted to give it a shot to egg donor option and her newly reconstructed uterus a good try (She had gone through extensive myomectomy). Her two IVFs and GIFT (Gamete in the Fallopian tube) procedures were 
unsuccessful. These failures caused her a great anguish, hopelessness and self -doubt.

She realized how angry she was with her mother who did not empower her and instead made her a damaged woman. She also felt that I was an impotent analyst and that her problem was far more complicated, beyond the scope of my expertise to be able to solve it. She was unsure about the help I could offer her. In the transference I turned in to an "Infertile analyst". She agreed with my interpretation of how she wished I could have had a magic formula to help her damaged uterus, damaged mind and damaged body. She felt I was letting her suffer in her despair and was being indifferent to her pain. I emerged as a controlling pre-oedipal mother who expected a total obedience and submission.

The decision about using an egg donor and who to ask became an obsession that agonized her for many months. She thought maybe she could ask her younger sister to become her egg donor. She asked herself if her sister could have a second thought about going through the medical procedure. She wanted her child to have her family genes and not to go to a stranger for eggs.

After several month of deliberation, she got her courage up to ask her sister Ann to see if she was willing to be her donor. Ann was a mother of two and was happily married. She was eager to help her older sister whom she was very fond of. Emily was static when she heard her sister accepted to be her donor egg. We tried to explore the meaning of using the eggs from her sister.

Her desire to use her sister eggs was so strong that she was not interested to explore the meaning of her decision. Her conscious desire was to have her family gene pull with her husband's sperm than using some stranger whom she did not know. She was set to have her own child and if her sister was willing to give her eggs, it meant that those were like her own eggs. It was like a dress they would share both. That is how she put it with a glee on her face. Shortly after this decision, she started to have fears about her sister's children who were her child's half siblings. How could she bear the thought of keeping it secret or have it out in open?

One happy thought countering her fear was "why not to become a big happy family?" She would carry the baby to term and everyone would understand and support her. She also thought she was being greedy to ask for her sister's eggs, which were not hers. To her it was like stealing! This self-accusation led to an association to an earlier memory about her mother. She recalled how her mother declared one day that how could she feed her children when there was hardly any food at home. Her father, an alcoholic was not helping the family when he spent money on his alcohol. Food was scares and the family had to deal with extreme deprivation.

Together we had done good deal of analytical work to help her with feelings of envy, greediness and stealing charge. She worked hard to overcome her doubt and move forward with her decision to enter into the world of motherhood.

After this unsettling emotional period was over, a much hopeful anticipation to "become a mother" prospect, made Emily overcome her disabling doubts. Her pregnancy was uneventful and she gave birth to a healthy baby girl. She brought her baby infant to one of her sessions. The baby had resemblance to her. She wanted to hear my reassurance that indeed her daughter looked like her. It was very important to her to hear it from me.

Two years later, after a period of hiatus in her treatment, she phoned to see me for a follow up visit. She was caught by surprise when she began feeling confused about her reaction toward her sister in a holiday family gathering. She felt her daughter seemed to go to her aunt (her biological mother) and she imagined her sister also made it obvious through her non-verbal interaction. She told me that she had never thought about the future encounters and her unexpected emotional reaction. She knew her sister had not revealed to her own two children about having volunteered to be an egg donor to her older sister. Emily was not prepared to talk about it with her daughter and was not sure that she would have wanted to disclose to her.

There was more work for us to do in therapy, exploring the meaning of her motivation giving promise to herself "the promise of anonymity". She felt competitive toward her sister and felt inferior to her. She struggled with the old feeling about her body that betrayed her.

\section{Discussion}

For men like Todd, infertility does not directly affect their traditional and gender role, although it can be profoundly disappointing and be experienced as performance failure and a failure of masculinity, as well. In some cultures, masculinity is directly linked to being able to produce children and as a woman's value to the man is diminished after her child bearing ends at menopause. There is no parallel to the visible personal bodily changes that the woman experiences in pregnancy.

Both men and women go through the physical and emotional turmoil of infertility. Infertility is both unique and complex. Although children are born through ART, the emotional impact of such reproductive methods is in need of further studies. The experience of going through fertility work up and ultimately having to go through many medical and psychological phases leading to a successful outcome is very unique for each individual. It can be a lonely and private experience for both men and women. It does affect their sense of which they are and who they imagined in their youth wanted to be. The fundamental value of capacity for creation has been so deeply rooted in sense of bodily self that individual belief systems about her/his sense of identity become challenged. Patient will struggle consciously and unconsciously with the meaning of borrowing eggs or sperms from other living beings.

The intense emotions erupt without knowing how to manage these strong emotions while they go through reproductive procedures.

Analysts and psychotherapists roles offering a holding environment at such trying times are each of these cases presents a complex of social, familial and cultural, unconscious and conscious elements which intern influence the ways in which navigate through the turmoil of their development challenges and unexpected losses. 
The earlier unconscious conflicts reappear and affect their sense of identity and their couple relationship.

\section{References}

1. The Guardian, UK, Wednesday 12 December 2012

2. Robert Nachtigall, Elizabeth Mehren (1991) Overcoming Infertility a practical strategy for navigating the emotional, medical, \& financial minefields of trying to have a baby. Doubleday Book 